\title{
Effects of Diode Laser Therapy and Stannous Fluoride on Dentin Resistance Under Different Erosive Acid Attacks
}

\author{
Vanara F. Passos, DDS, MSc, PhD,,2 Mary Anne S. Melo, DDS, MSc, PhD, Francisco F.C. Silva, \\ Lidiany Karla A. Rodrigues, DDS, MSc, PhD, and Sérgio L. Santiago, DDS, MSc, PhD ${ }^{1}$
}

\begin{abstract}
Objective: This in vitro study aimed to evaluate the effect of a low intensity diode laser $\left(\lambda=808 \mathrm{~nm} ; 60 \mathrm{~J} / \mathrm{cm}^{2}\right)$ associated with stannous fluoride on the inhibition of dentin erosion by assessing percentage of superficial hardness loss (\%SHL) and calcium release into the acid solution. Materials and methods: Human root dentin slabs were assigned to eight groups $(n=10)$, according to treatments (control, stannous fluoride, diode laser therapy, and the combination of stannous fluoride and laser therapy), and acid challenge (hydrochloridric or citric acid). All slabs were subjected to a previous $2 \mathrm{~h}$ acquired pellicle formation; laser and fluoride treatments were performed according to the groups. Subsequently, the slabs were exposed to erosive challenge $(0.01 \mathrm{M}$ hydrochloridric acid or citric acid $1 \%$ for $60 \mathrm{sec}$ ). Additionally, calcium released into the acid solution during erosive challenge was analyzed by photometric test. Data were analyzed by ANOVA followed by Tukey's test $(p<0.05)$. Results: Mean values $( \pm \mathrm{SD})$ for $\% \mathrm{SHL}$ of treated groups did not present statistically significant differences, regardless of the erosive challenge. However, in relation to released calcium concentration, groups treated with laser presented statistically significant lower calcium loss under hydrochloridric acid challenge $(p<0.001)$. To groups under citric acid attack, only the combination of treatments $(p=0.037)$ was able to show a protective effect on dentin. Conclusions: Under the conditions of this study, $808 \mathrm{~nm}$ diode laser with or without stannous fluoride could effectively reduce dentin surface loss under both acid exposures. Only calcium concentration analysis was sensitive enough to measure the effects under the tested conditions.
\end{abstract}

\section{Introduction}

C ONTROL OF EROSIVE ACID ATTACKS ON DENTAL TISSUES is one of major problems in prevention and therapy of dental erosion in dental clinical practice. ${ }^{1}$ Severe erosive injuries may affect not only the enamel surface but can also lead to the exhibition of the coronary or root dentin tissue. ${ }^{2}$ Demineralization in dentin happens more quickly because the dentin is less densely packed with minerals than the enamel, and less able to resist acids. ${ }^{3}$ In advanced stages of dental erosion, dentin becomes increasingly exposed, and hypersensitivity as well as loss of tooth anatomy and vertical dimension may occur. ${ }^{4}$

Several methods have been proposed to prevent the progression of dental erosion, especially of those that may provide increased acid resistance or remineralization of tooth surfaces. ${ }^{5,6}$ The most widely used approach in management of dental erosion is the use of fluorides, which is available in dentifrices, solutions, or varnishes. ${ }^{5,7,8}$ The antierosive ability of fluoride therapy is still under debate, and little is known about the mode of action of stannous fluoride $\left(\mathrm{SnF}_{2}\right)$ in dentin. However, previous studies have suggested that fluoride preparations containing stannous ions present promising protective effects against cyclic erosive attacks, showing $\mathrm{SnF}_{2}$ as the most effective solution to reduce tissue loss. 9,10

Numerous studies have investigated laser therapy either alone or in combination with a different fluoride source as a preventive approach against the development of dental erosion, and a significant synergism in reducing demineralization and increasing fluoride retention has been found. ${ }^{1-13}$ The effects of laser irradiation associated with fluoride application have been reported using a variety of high-power laser sources, such as $\mathrm{CO}_{2}$, Nd:YAG, Argon, and Er:YAG. Even so, the high cost and possible thermal alterations have limited the access to these instruments. Laser energy provided at particular wavelengths in the visible and infrared regions from a variety of low-power sources has increased the resistance of tooth structure to mineral loss without the drawbacks of high-power lasers. ${ }^{12,13}$

\footnotetext{
${ }^{1}$ Post-graduation Program, Faculty of Pharmacy, Dentistry and Nursing, Federal University of Ceará, Brazil.
}

${ }^{2}$ University of Fortaleza, Ceará, Brazil. 
The acids involved in erosive attacks are stronger than the organic acids involved in dental caries. The most important sources of acids are those found in the stomach (gastric acids from regurgitation and reflux disorders) and from daily diet (acidic foods and drinks). ${ }^{14,15}$ Stomach juice is source of hydrochloric acid, which, in cases of gastric or vomiting disorders, presents a constant contact with the dental tissues. Moreover, acidic drinks and food have been reported to cause extrinsic dental erosion. ${ }^{16}$

Taking into consideration the lack of data related to erosion-prevention action of $\mathrm{SnF}_{2}$ on dentin substrate or the effect of its combination with other preventive measures, the hypothesis under investigation was that the interaction between $\mathrm{SnF}_{2}$ and diode laser irradiation can modify the characteristics and properties of human dentin, affecting their protection against dental erosion. The objective was to test the proposed hypothesis, considering erosive challenges created by different acidic sources.

\section{Material and Methods}

\section{Experimental design}

The factors under investigation were (1) treatment (four levels): absence (control), diode laser therapy $(808 \mathrm{~nm})$, $\mathrm{SnF}_{2}(0.4 \%)$, and the combination of diode laser and stannous fluoride; and (2) erosive challenge (two levels): hydrochloric acid and citric acid. The dependent variables were, respectively: calcium concentration released during an erosive attack $\left(\mathrm{mmol} / \mathrm{mm}^{2}\right)$, quantitatively evaluated by photometric determination, and percentage of surface hardness loss (\%SHL), quantitatively evaluated by the difference of superficial microhardness means values after treatments. For each treatment, 10 specimens were prepared.

\section{Specimen preparation}

Dentin slabs $(4 \times 4 \times 2 \mathrm{~mm})$ were cut from roots of caries free human third molars. The Human Ethics Committee of Federal University Institution has approved this study (\#035/ 2011). The teeth were cleaned and stored in $0.01 \%(\mathrm{w} / \mathrm{v})$ thymol solution at $4^{\circ} \mathrm{C}$ prior to the experiment. The slabs were sequentially flattened and polished using a watercooled mechanical grinder (Ecomet/Automet 300 Polisher, Buehler, Lake Bluff, IL) with 400, 600, and 1,200 grit $\mathrm{Al}_{2} \mathrm{O}_{3}$ papers and polished on cloths with a $1.0 \mu \mathrm{m}$ diamond suspension (Alpha Micropolish, Buehler).

In order to establish a standardization of samples, the slabs were selected by surface hardness prior to the randomized distribution. The surface microhardness was determined by performing five indentations in the center of the dentin surface for selection and randomized distribution purposes (Knoop diamond, 25g, 5 s) (FM100, Future Tech, Tokyo, Japan). In order to minimize the interference on dentin dehydration on the measurements, the slabs were allowed to dry for $30 \mathrm{~min}$ after they were removed from the humid environment where they were stored. Eighty samples with values ranging from 53 to 65 Knoop hardness number $(\mathrm{KHN})$ were selected and randomly assigned according to a computergenerated randomization list into the eight groups $(n=10)$.

Afterwards, the specimens were covered with an acidresistant varnish in a dark color (Colorama, CEIL Coml. Exp. Ind. Ltd., São Paulo, SP, Brazil), leaving a circum- ferential exposed area of $7.065 \mathrm{~mm}^{2}$ in their central area to be subjected to the treatments. The defined area promoted similar exposed surfaces for calcium analysis.

\section{Salivary pellicle formation}

To mimic a clinical situation with salivary protective systems presence, salivary pellicle formation was performed on dentin surfaces according to a previous study. ${ }^{17}$ Briefly, fresh saliva samples were collected from groups of 15-20 volunteers without active carious lesions, erosions, or salivary dysfunction. The subjects did not eat or smoke during the $8 \mathrm{~h}$ period before sampling. Saliva was stimulated with paraffin wax for $5 \mathrm{~min}$. Saliva from the 1st min of chewing was swallowed, and the rest was collected and deposited into a $50 \mathrm{~mL}$ centrifuge tube. The saliva samples were centrifuged for $10 \mathrm{~min}$ at $2000 \mathrm{rpm}$ in a precooled centrifuge $\left(4^{\circ} \mathrm{C}\right)(5415 \mathrm{R}$, Eppendorf, Brazil). The clear fluid above the sediments was pooled and used for pellicle formation. Each group of dentin slabs was independently immersed in clarified saliva and incubated during $2 \mathrm{~h}$ before each experimental period under agitation at $100 \mathrm{rpm}(5 \mathrm{~mL}$ per slab) at simulated cavity oral temperature $\left(37^{\circ} \mathrm{C}-\right.$ Bacteriological Incubator - Tecnal - Piracicaba, SP, Brazil) prior to erosive challenges.

\section{Gallium-aluminum-arsenide (GaAlAs) laser treatment and fluoride application}

The samples were irradiated with a low-level GaAlAs diode laser "Whiteness lase II" (DMC, São Carlos, SP, Brazil) at a wavelength of $808 \mathrm{~nm}$ in the infrared spectrum. This laser consisted of a class 3B system with a continuous wave and an adjustable output energy ranging from 30 to $100 \mathrm{~mW}$ and a spot size of $0.6 \mathrm{~mm}$. A power meter "Lasermate" (Coherent Inc, Santa Clara, CA) was used to measure the maximum output power.

To promote an area of radiation that included the whole surface of the selected area, the laser probe was held perpendicular to the tooth surface. Energy density of $60 \mathrm{~J} / \mathrm{cm}^{2}$ was used to the treatment, as this energy density was shown to be effective in a previous study. ${ }^{13}$ Using the output power of $100 \mathrm{~mW}$, the necessary exposure times in order to reach the chosen densities were calculated according the following formula: density of energy $=$ power $(\mathrm{W}) \times$ time $(\mathrm{sec}) / a r e a\left(\mathrm{~cm}^{2}\right)$.

According to the group, a single application of $0.4 \% \mathrm{SnF}_{2}$ varnish (Omni Gel, 3M ESPE) or a placebo gel containing a similar content of varnish without the $\mathrm{SnF}_{2}$ (colorless gel with hydroxyethyl cellulose and glycerin) was performed using a cotton swab. The gel was applied on the specimens for the same duration of laser application $(90 \mathrm{sec})$.

\section{Erosive demineralization}

After treatments, samples from the same groups were immersed in $0.01 \mathrm{M}$ hydrochloric acid, pH 2.0 (Synth, Diadema, SP, Brazil) (5 mL per specimen) or citric acid $1 \%$, $\mathrm{pH} 2.3$ for $60 \mathrm{sec}$ under agitation. This procedure refers to simulating an acid challenge, representing the normal values similar to the conditions of gastric reflux (gastric secretions $\mathrm{pH}<4$ ) or of consuming citrus juices. The immersion was performed at room temperature $\left(\sim 20^{\circ} \mathrm{C}\right)$. Following this, the specimens were rinsed in deionized water $(10 \mathrm{sec})$, and 
carefully dried with absorbent paper. The hydrochloric acid and citric acid solutions were collected after the slab exposure and then they were transferred to coded plastic containers and stored at $4{ }^{\circ} \mathrm{C}$ until analysis for calcium release determination.

\section{Photometric determination of calcium release}

The calcium concentration of erosive dissolution from all specimens was determined. For specimens subjected to hydrochloric acid, the calcium release was determined spectrometrically by colorimetric essay using the Arsenazo III method. ${ }^{18}$ In colorimetric analysis, Arsenazo III reacts with calcium in an acidic solution forming a blue purple complex, in which the intensity developed is proportional to the calcium concentration in the solution. Absorption was be determined at $\lambda=630 \mathrm{~nm}$. For specimens subjected to citric acid, atomic absorption spectrometric determination was performed. Prior to analysis, $1 \%$ lanthanum was added to the samples in order to counteract the negative effect of phosphorus on the calcium sensitivity of the spectrometer. The calcium release $\left(\mathrm{nmol} / \mathrm{mm}^{2}\right)$ was calculated.

\section{$\%$ SHL assessment}

Before and after the erosive challenge, the surface hardness of the dentin specimens was measured, as previously described for the baseline determinations. The post analysis (indentation) was performed at $100 \mu \mathrm{m}$ from initial baseline indentation. \%SHL was calculated by the formula: $\% \mathrm{SHL}=\left[\left(\mathrm{SH}_{\text {before }}-\mathrm{SH}_{\mathrm{after}}\right) \times 100 / \mathrm{SH}_{\text {before }}\right] .^{18}$

\section{Statistical analysis}

The Kolmogorov-Smirnov test was applied to all groups to test for the normal distribution of errors. Because the values were normally distributed across all of the groups, a parametric method was chosen for the statistical analysis. ANOVA was performed to analyze \%SHL and quantities of calcium loss. Tukey's post-hoc tests were applied, when necessary, in cases in which ANOVA revealed significant differences. $\mathrm{SH}_{\text {before }}$ and $\mathrm{SH}_{\text {after }}$ were determined by paired $t$ test. Statistical procedures were performed with the Statistical Package for Social Sciences (SPSS 17.0) for Windows. The level of significance was set at $5 \%$.

\section{Results}

Figure 1 shows the mean of percentage of surface hardness loss after the erosive challenge to each group. ANOVA performed for the data of $\%$ SHL showed no statistically significant difference among the groups. When applying the hydrochloric acid, none of the treatments tested were able to provide significant protection $(p=0.918)$. Figure 2 expresses the mean \%SHL after the erosive challenge by citric acid. In this situation, there is a trend toward lower demineralization of dentin in samples treated with the combination of $\mathrm{SnF}_{2}$ and diode laser irradiation compared with other groups, but the difference among them was not statistically significant $(p=0.679)$.

Regarding the results of calcium release expressed in Table 1, diode laser irradiation combined or not combined with $\mathrm{SnF}_{2}$ provided significantly lower dentin dissolution when subjected to $\mathrm{HCl}$ attack $(p<0.001)$. For the groups exposed to citric acid, the calcium analyses shows that the $\mathrm{SnF}_{2}$ application and diode laser irradiation individually were able to show a trend toward differing from control; however, only the combination was able to show a clearly significant difference from the control group $(p<0.035)$.

\section{Discussion}

In the present study, the protective effect of the lowpower diode laser, combined or not combined with $\mathrm{SnF}_{2}$, in preventing dentin erosion when subjected to different acid attacks, was investigated. In order to simulate the clinical situation as closely as possible, erosive challenge protocol was performed using representative acids from most common acidic sources that an individual is subjected to in a daily routine. ${ }^{15,16}$ Human saliva was also used in this study. Several characteristics and properties of saliva play an important role in dental erosion. ${ }^{19}$ In erosive processes, the salivary pellicle that forms on the tooth surface serves as a natural protective barrier against dental erosion. ${ }^{20}$ As the present study was planned as a primary study testing the possible preventive effect of $\mathrm{SnF}_{2}$ and diode laser irradiation against dentine erosion, only short term erosion was performed.

The hypothesis of the present study that interaction between $\mathrm{SnF}_{2}$ and diode laser (low-power) irradiation could improve the acid resistance of treated dentine was accepted. $\mathrm{SnF}_{2}$ varnish alone did not prevent dentin erosion under the

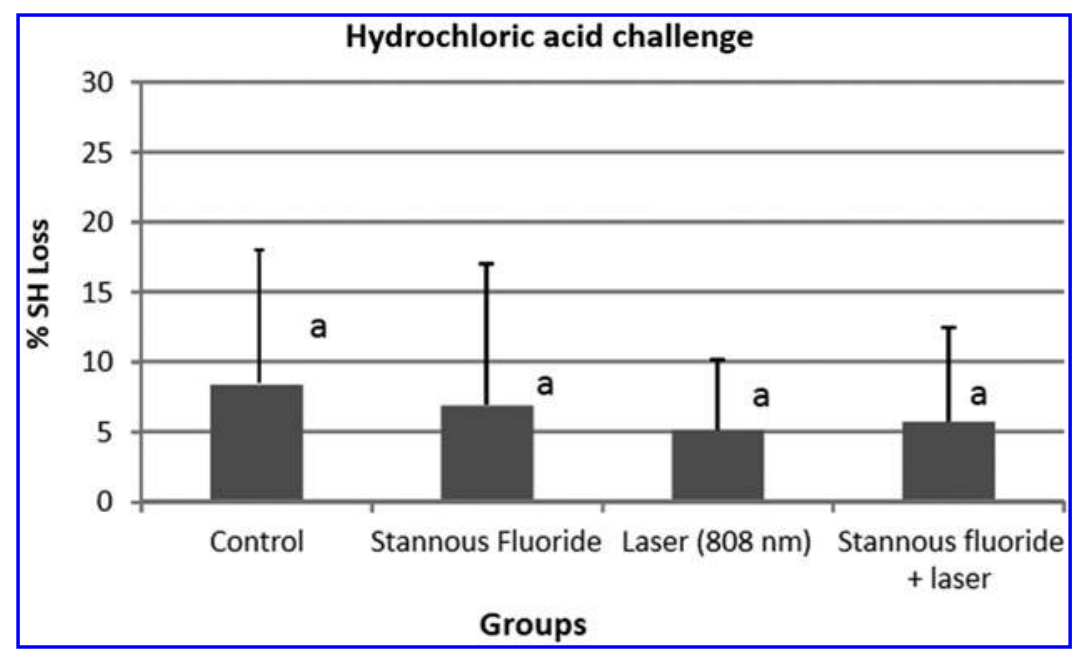

FIG. 1. Mean and standard deviation of percentage of surface hardness loss (\%SHL) for human root dentin specimens with each treatment, after which specimens were subjected to hydrocloric acid. Similar letter (a) denotes no statistically significant differences. 
FIG. 2. Mean and standard deviation of percentage of surface hardness loss (\%SHL) for human root dentin specimens with each treatment, after which specimens were subjected to citric acid. Similar letter (a) denote no statistically significant differences.

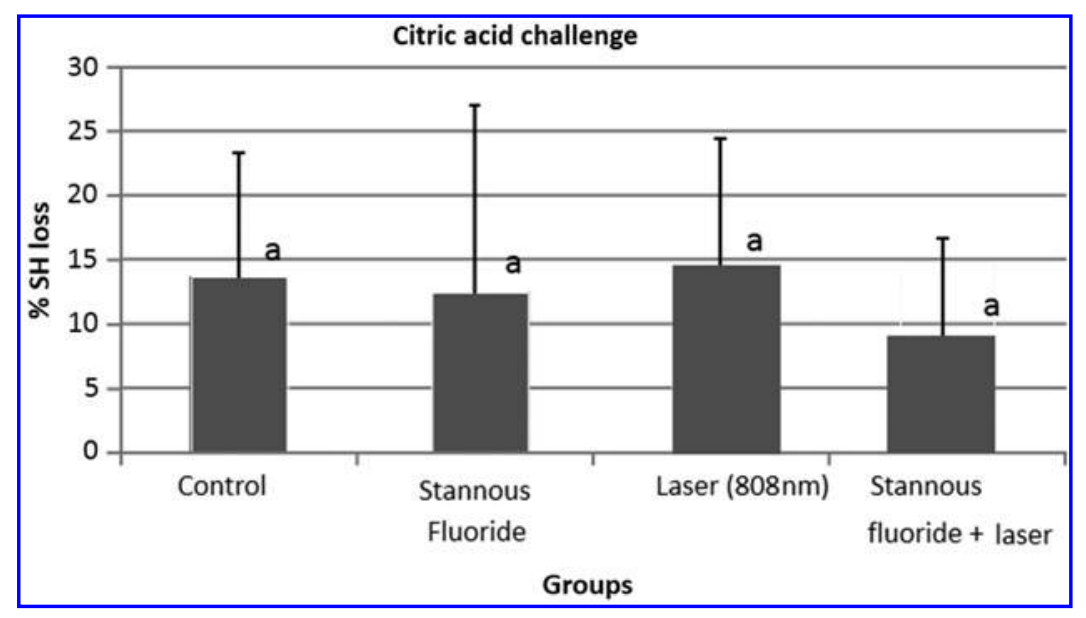

conditions of this study. GaAlAs diode laser irradiation alone was able to reduce the calcium loss only under $\mathrm{HCl}$ erosive attack. However, this preventive result was not clearly observed after citric acid challenge.

The physicochemical process of dental erosion involves mainly mineral dissolution of the involved tissue; however, the dentin organic matrix content plays an important role in its development, taking up a great area in the intertubular structure of dentin, and has been shown to retard dentin demineralization during an acid attack. ${ }^{21}$ A complete and clear mechanism has not been proposed to explain the effect of low-power laser on dentin. Some have attributed the effect to the block dentin diffusion (organic matrix blocking) promoted by lower-energy laser treatment, in which the energy modifies organic matrix to obliterate the diffusion channels. $^{22,23}$ A similar mechanism has been suggested for the effect of low-energy laser on enamel demineralization reduction; even though the difference in the mineral content between these hard tissues is known. ${ }^{24,25}$

To verify the effects of laser-induced reduction in this particular tissue, previous studies have investigated the use of low-powered diode lasers combined or not combined

TABle 1. CALCIUM Loss (NMOL/MM²)

FROM EACH TREATMENT Following InCUbation FOR 60 SEC IN HCL AND CITRIC ACID

\begin{tabular}{|c|c|c|}
\hline $\begin{array}{l}\text { Erosive } \\
\text { challenge }\end{array}$ & Treatments & $\begin{array}{c}\text { Mineral loss } \\
\text { after } 60 \mathrm{sec} \text {, } \\
\text { nmol/ } / \mathrm{mm}^{2} \\
\text { Calcium release }\end{array}$ \\
\hline $\begin{array}{l}\text { Hydrocloric } \\
\text { acid } 0.01 \mathrm{M}, \\
\text { pH } 2.0\end{array}$ & $\begin{array}{l}\text { Control } \\
\text { Stannous fluoride } \\
\text { Laser } \\
\text { Stannous fluoride + laser }\end{array}$ & $\begin{array}{c}59.12 \pm 15.20^{\mathrm{a}} \\
59.90 \pm 20.60^{\mathrm{a}} \\
9.06 \pm 11.91^{\mathrm{b}} \\
11.58 \pm 8.98^{\mathrm{b}}\end{array}$ \\
\hline$p$ Values & & $p<0.001$ \\
\hline $\begin{array}{l}\text { Citric acid } 1 \%, \\
\text { pH } 2.0\end{array}$ & $\begin{array}{l}\text { Control } \\
\text { Stannous fluoride } \\
\text { Laser } \\
\text { Stannous fluoride + laser }\end{array}$ & $\begin{array}{l}36.11 \pm 32.15^{\mathrm{a}} \\
19.81 \pm 9.98^{\mathrm{ab}} \\
16.50 \pm 9.13^{\mathrm{ab}} \\
13.69 \pm 6.57^{\mathrm{b}}\end{array}$ \\
\hline$p$ Values & & $p=0.035$ \\
\hline
\end{tabular}

Data significantly different within one column of each challenge are followed by distinct superscripts. with a fluoride application. ${ }^{12,20}$ Dentin irradiation with a diode laser operating at $60 \mathrm{~J} / \mathrm{cm}^{2}$ may induce inhibitory effects on root dentin demineralization caused by hydrochloric acid $0.1 \mathrm{M} .^{13}$ Knowing that laser-tissue interactions are mainly controlled by laser parameters, the combination of suitable wavelength, energy density, exposure time, and emission mode may represent a critical aspect for reaching satisfactory outcome.

Nevertheless, diode laser irradiation was not effective for citric acid challenge, probably because citric acids have a double action; one action is the loss of calcium by hydrogen ions, and the other is the fact that citric acid acts as a chelator, once the citrate anion may complex with calcium removing it from the dental structure. The simultaneous use of laser and $\mathrm{SnF}_{2}$ was effective in reducing calcium loss in both challenges. This action may be related to the capacity of the laser to increase fluoride uptake to dental substrates, forming a reservoir of fluoride, such as calcium fluoride, to avoid the calcium loss during the erosion.

The mechanism for the protective effect of $\mathrm{SnF}_{2}$ against erosion can be explained by the blocking diffusion process. ${ }^{26}$ The dentinal surface is covered by a layer containing the reaction products of $\mathrm{SnF}_{2}$ and hydroxyapatite, such as $\mathrm{Sn}_{2} \mathrm{OHPO}_{4}, \mathrm{Sn}_{3} \mathrm{~F}_{3} \mathrm{PO}_{4}, \mathrm{Ca}\left(\mathrm{SnF}_{3}\right)_{2}$ or $\mathrm{CaF}_{2}$ salts, which can obliterate patent dentinal tubules. However, in contrast to previous studies, ${ }^{27-29} \mathrm{SnF}_{2}$ alone was not able to reduce the demineralization and mineral loss of dentine. The stannous effect is highlighted after the erosive demineralization exposing the organic matrix and phosphoproteins. These products may attract the stannous ions, which are then retained in this layer, and might accumulate in the underlying mineralized tissue. ${ }^{30}$ Therefore, in the current study, the erosive challenge was performed after the preventive treatment, reducing the power of penetration of fluoride. According Ganss et al. ${ }^{10}$ the effects and action of $\mathrm{SnF}_{2}$ on enamel are not similar to dentin, because of the presence of the organic matrix that may modify the protective effect of fluorides.

For in depth characterization, two different methods for evaluation of initial erosions under standardized conditions were selected: microhardness measurements and calcium analysis. ${ }^{31}$ Considering that softening of dentin is a key factor that links to its loss, these methods would give valuable information about the studied conditions. Previous studies have reported that calcium analysis is a sensitive 
method that can detect the small changes that occur in tissue surfaces following acid challenge and fluoride treatments. ${ }^{32,33}$ However, according Schlueter et al. ${ }^{34}$ the microhardness method presents inherent limitations because of the alteration that occurs in the exposed matrix, leading to high standard deviations observed for this analysis. Profilometry is another approach for quantification of mineral loss. This option was not performed in the present study because of the limitation of its applicability on initial erosive effects. ${ }^{35}$

\section{Conclusions}

This in vitro study showed that the effects of diode laser alone or simultaneously with $\mathrm{SnF}_{2}$ suggest a protective action to dentin dissolution when under exposure to acid challenges. However, further investigations should be considered to clarify the exact mechanism of the action of the diode laser and its interaction with $\mathrm{SnF}_{2}$, as well as exploring more pronounced effects by the combination of these treatments.

\section{Author Disclosure Statement}

No competing financial interests exist.

\section{References}

1. Gambon, D.L., Brand, H.S., and Veerman, E.C. (2012) Dental erosion in the 21st century: what is happening to nutritional habits and lifestyle in our society? Br. Dent. J. 213, 55-57.

2. Ganss, C., Lussi, A., Scharmann, I., Weigelt, T., Hardt, M., Klimek, J., and Schlueter, N. (2009). Comparison of calcium analysis, longitudinal microradiography and profilometry for the quantitative assessment of erosion in dentine. Caries Res. 43, 422-429.

3. Wiegand, A., Rios, D., Honório, H.M., et al. (2009). Insights into preventive measures for dental erosion. J. Appl. Oral Sci. 17, 75-86.

4. Lussi, A., Schlueter, N., Rakhmatullina, E., and Ganss, C. (2011). Dental erosion-an overview with emphasis on chemical and histopathological aspects. Caries Res. 45 (Suppl. 1), 2-12.

5. Messias, D.C.F., Maeda, F.A., Turssi, C.P., and Serra, M.C. (2011). Effect of dentifrices against hydrochloric acidinduced erosion. Oral Health Prev. Dent. 9, 269-273.

6. Willershausen, B., Schulz, D., and Burkhard, G. (2009). In vitro evaluation of enamel remineralisation by a casein phosphopeptide-amorphous calcium phosphate paste. Oral Health Prev. Dent. 7, 13-21.

7. Amaechi, S.M. (2005). Dental erosion: possible approaches to prevention and control. J Dent. 33, 243-252.

8. Wiegand, A., and Attin, T. (2003). Influence of fluoride on the prevention of erosive lesions - a review. Oral Health Prev. Dent. 1, 245-253.

9. Ganss, C., Schlueter, N., Hardt, M., Schattenberg, P., and Klimek, J. (2008). Effect of fluoride compounds on enamel erosion in vitro: a comparison of amine, sodium and stannous fluoride. Caries Res. 42, 2-7.

10. Ganss, C., Lussi, A., Sommer, N., Klimek, J., and Schlueter, N. (2010). Efficacy of fluoride compounds and stannous chloride as erosion inhibitors in dentine. Caries Res. 44, 248-252.

11. Sayed, A., Hegde, V., and Thukral, N. (2012). Prevention of enamel from erosion by laser activated fluoride treatment. J. Dent. Lasers 6, 7-10.
12. Vlacic, J., Meyers, I.A., and Walsh, L.J. (2007). Laseractivated fluoride treatment of enamel as prevention against erosion. Aust. Dent. J. 52, 175-180.

13. de Melo, M.A., Passos, V.F., Alves, J.J., Barros, E.B., Santiago, S.L., and Rodrigues, L.K. (2011). The effect of diode laser irradiation on dentin as a preventive measure against dental erosion: an in vitro study. Lasers Med Sci. 26, 615-621.

14. Bartlett, D.W., Fares, J., Shirodaria, S., Chiu, K., Ahmad, N., and Sherriff, M. (2011). The association of tooth wear, diet and dietary habits in adults aged 18-30 years old. J Dent. 39, 811-816.

15. Ranjitkar, S., Kaidonis, J.A., and Smales, R.J. (2012). Gastroesophageal reflux disease and tooth erosion. Int. J. Dent. 2012, 479850.

16. Li, H., Zou, Y., and Ding, G. (2012). Dietary factors associated with dental erosion: a meta-analysis. PLoS One 7, e42626.

17. Melo, M.A.S., Silva, F.F.C., Passos, V.F., Santiago, S.L., and Rodrigues, L.K. (2013). Investigation on light-assisted preventive effects on dentin erosion. Photonics Lasers Med. 2, 209-216.

18. Barbosa. R.P., Pereira-Cenci, T., Silva, W.M., Coelhode-Souza, F.H., Demarco, F.F., and Cenci, M.S. (2012). Effect of cariogenic biofilm challenge on the surface hardness of direct restorative materials in situ. J. Dent. 40, 359-363.

19. Buzalaf, M.A., Hannas, A.R., and Kato, M.T. (2012). Saliva and dental erosion. J. Appl. Oral Sci. 20, 493-502.

20. Magalhães, A.C., Rios, D., Machado, M., Silva, S.M.B., Lizarelli, R.D.F.Z., Bagnato, V.S., and Buzalaf, M.A.R. (2008). Effect of Nd:YAG irradiation and fluoride application on dentine resistance to erosion in vitro. Photomed. Laser Surg. 26, 559-563.

21. Magalhães, A.C., Wiegand, A., Rios, D., Honório, H.M., and Buzalaf, M.A. (2009). Insights into preventive mearures for dental erosion. J. Appl. Oral Sci. 17, 75-86.

22. Liu, Y., and Hsu, C.Y. (2007). Laser-induced compositional changes on enamel: a FT-Raman study. J. Dent. 35, 226-230.

23. Chin-Ying, S.H., Xiaoli, G., Jisheng, P., and Wefel, J.S. (2004). Effects of $\mathrm{CO}_{2}$ laser on fluoride uptake in enamel. J. Dent. 32, 161-167.

24. Liu, Y., Hsu, C.Y., Teo, C.M., and Teoh, S. (2013). Subablative Er:YAG laser effect on enamel demineralization. Caries Res. 47, 63-68.

25. Vieira, A.H., Passos, V.F., de Assis, J.S., Mendonça, J.S., and Santiago, S.L. (2009). Clinical evaluation of a $3 \%$ potassium oxalate gel and a GaAlAs laser for the treatment of dentinal hypersensitivity. Photomed. Laser Surg. 27, 807-812.

26. Tepper, S.A., Zehnder, M., Pajarola, G.F., and Schmidlin, P.R. (2004). Increased fluoride uptake and acid resistance by $\mathrm{CO}_{2}$ laser irradiation through topically applied fluoride on human enamel in vitro. J. Dent. 32, 635-641.

27. Willumsen, T., Ogaard, B., Hansen, B.F., and Rølla, G. (2004). Effects from pretreatment of stannous fluoride versus sodium fluoride on enamel exposed to $0.1 \mathrm{M}$ or $0.01 \mathrm{M}$ hydrochloric acid. Acta Odontol. Scand. 62, 278281.

28. Yu, H., Wegehaupt, F.J., Zaruba, M., Becker, K., Roos, M., Attin, T., and Wiegand, A. (2010). Erosion-inhibiting potential of a stannous chloride-containing fluoride solution under acid flow conditions in vitro. Arch. Oral Biol. 55, 702-705. 
29. Young, A., Thrane, P.S., Saxegaard, E., Jonski, G., and Rölla, G. (2006). Effect of stannous fluoride toothpaste on erosion-like lesions: an in vivo study. Eur. J. Oral Sci. 114, 180-183.

30. Comar, L.P., Gomes, M.F., Ito, N., Salomão, P.A., Grizzo, L.T., Magalhães, A.C. (2012). Effect of $\mathrm{NaF}, \operatorname{SnF}(2)$, and $\mathrm{TiF}(4)$ toothpastes on bovine enamel and dentin erosionabrasion in vitro. Int. J. Dent. 2012, 134350.

31. Shellis, R.P., Ganss, C., Ren, Y., Zero, D.T., and Lussi, A. (2011). Methodology and models in erosion research: discussion and conclusions. Caries Res. 45 (Suppl. 1), 69-77.

32. Hjortsjö, C., Jonski, G., Young, A., and Saxegaard, E. (2010). Effect of acidic fluoride treatments on early enamel erosion lesions - a comparison of calcium and profilometric analyses. Arch. Oral Biol. 55, 229-234.

33. Hannig, C., Becker, K., Yankeu-Ngalene, V.E., and Attin, T. (2008). Applicability of common methods for short time erosion analysis in vitro. Oral Health Prev. Dent. 6, 239-248.
34. Schlueter, N., Hara, A., Shellis, R.P., and Ganss, C. (2011). Methods for the measurement and characterization of erosion in enamel and dentine. Caries Res. 45 (Suppl.), 13-23.

35. Passos, V.F., Melo, M.A., Vasconcellos, A.A., Rodrigues, L.K., and Santiago, S.L. (2013). Comparison of methods for quantifying dental wear caused by erosion and abrasion. Microsc. Res. Tech. 76, 178-183.

Address correspondence to: Sergio Lima Santiago Department of Restorative Dentistry Postgraduate Program in Dentistry Faculty of Pharmacy, Dentistry and Nursing Federal University of Ceará Cap. Francisco Pedro St S/N Fortaleza, Ceará 60430-170 Brazil

E-mail: sergiosantiago@ufc.br 